\title{
Posibilidades del documental transmedia iberoamericano en la visibilización de la comunidad LGBTQI: los casos de La primavera rosa y La otra orilla
}

\author{
Santiago López Delacruz \\ Universidad de la República de Uruguay \\ santiago.lopez@fic.edu.uy \\ https://orcid.org/0000-0001-9555-5428
}

\section{Possibilities of the Ibero-American transmedia documentary in the visibility of the LGBTQI community: the cases of La primavera rosa and La otra orilla}

\begin{abstract}
RESUMEN
El documental transmedia con fines sociales posee una relevancia cada vez mayor en la actual cultura audiovisual, evidenciando una modificación en el accionar de la rea-

lización cinematográfica suscitada por la hibridación de soportes, formatos y lenguajes y la apertura de un espacio de producción multiforme que expande el uso de distintas instancias discursivas. Fomentadas por la creación y la participación creativa de sus espectadores, resulta pertinente indagar sobre las estrategias utilizadas por el documental transmedia iberoamericano para visibilizar las problemáticas de la comunidad LGBTQI desde tres factores propios de la era transmediática: la convergencia, la inteligencia colectiva y la cultura participativa. Mediante el estudio de caso de La primavera rosa y La otra orilla, dos producciones transmediales de carácter social, se propone como objetivo explorar las posibilidades del formato a la hora de generar movilización social y cultural. Debido a la convergencia mediática de

la era digital, en el panorama audiovisual actual se genera una proliferación de estrategias participativas donde los movimientos sociales utilizan la representación documental como herramienta ideológica que trata de incidir en los discursos que circulan en la sociedad tanto a nivel simbólico como de carácter ideológico.
\end{abstract}

PALABRAS CLAVE

Comunidad LGBTQI; Convergencia mediática; Cultura participativa; Documental transmedia; Inteligencia colectiva.

\section{ABSTRACT}

The transmedia documentary with social purposes has an increasing relevance in the current audiovisual culture, evidencing a modification in the actions of the cinematographic production caused by the hybridization of supports, formats and languages and the opening of a multiform production space that expands the use of different discursive instances. Fostered by the creation and creative participation of its viewers, it is pertinent to inquire about the strategies used by the Ibero-American transmedia documentary to make visible the problems of the LGBTOI community from three factors typical of the transmedia era: convergence, collective intelligence and culture participatory. Through the case study of La primavera rosa and La otra orilla, two social transmedia productions, the objective is to explore the possibilities of the format when it comes to generating social and cultural mobilization. Due to the media convergence of the digital age, in the current audiovisual panorama a proliferation of participatory strategies is generated where social movements use documentary representation as an ideological tool that tries to influence the discourses that circulate in society both at a symbolic and an ideological level.

\section{KEYWORDS}

LGBTQI Community; Media convergence; Participatory culture; Transmedia documentary; Collective intelligence. 


\section{Introducción}

El panorama actual de la realización audiovisual hace cada vez más continuo el hallazgo de hibridaciones dentro de los campos de la comunicación y la cultura, modificando el accionar de los medios de comunicación tradicionales en su vínculo con lo social. Específicamente hablando de la realización documental, el apogeo de las producciones con base en lo transmedial ha provocado una diversificación de la producción, la recepción y la circulación de contenidos audiovisuales, abriendo un espacio de producción horizontal que fomenta la creación y la participación de los espectadores desde la creatividad tanto individual como colectiva.

Se entiende por transmedia ${ }^{1}$ una estrategia narrativa generada a través de diversas plataformas concebida como el "arte de crear mundos" desde la convergencia de los medios y la dependencia de las comunidades activas de conocimiento (Jenkins, 2008). El formato transmediático multiplica usos y aplicaciones de distintos soportes y lenguajes: cada medio es importante para contribuir a una narrativa en común expandiendo diferentes sistemas de significación (Scolari, 2013) y "el contenido generado por los usuarios de la obra es esencial, hasta tal punto que una narrativa transmedia, si no posee este tipo de aportaciones, no se puede considerar como tal" (Gifreu-Castells, 2015a, p. 31).

Como expresa Liuzzi, "las narrativas transmedia han impulsado nuevas formas de produciry consumir documentales. Su aporte es fundamental para comprender las diferentes dinámicas en que las audiencias actuales se apropian de los relatos distribuidos de no-ficción" (2015, p. 133). Se explicita un aporte desde lo social por parte del documental transmedia puesto que este tipo de realizaciones flexibiliza géneros, formatos y discursos en el campo de la no ficción (Gifreu-Castells, 2015a), comprendiendo temáticas socioculturales desde variados recursos digitales.

Las producciones transmediales nacen como resultado de tres factores suscitados con el desarrollo y la masificación de las Tecnologías de la información y la comunicación en el presente siglo: la convergencia mediática, la cultura participativa y la inteligencia colectiva. En relación a la convergencia mediática, podemos definirla como el flujo de contenido que circula a través de múltiples plataformas integrando múltiples textos para crear una narración que no se confina a un único medio, puesto que la circulación de contenidos mediáticos siempre está sujeta a la participación activa de los consumidores (Jenkins, 2008). La convergencia permite que diversas fuentes de información se combinen para crear un ecosistema de participación activo entre los usuarios, fomentando la interacción y el intercambio de actividades desde diversos niveles, lo que da lugar a una cultura de la participación.

Por cultura participativa se entiende una cultura que invita a los consumidores a participar de forma activa creando y difundiendo nuevos contenidos en la creación y difusión de nuevos contenidos" (Jenkins y Tatjer, 2010), transformando la experiencia de consumo y el concepto mismo de espectador, reconfigurado en protagonista activo del nuevo modo transmediático. La mentalidad de la cultura participativa "se basa en crear textos mediáticos que el público diverso (cuyos propósitos son dispares) pueda poner en circulación. Así, la gente determina el contexto de ese contenido mientras lo esparce por sus círculos sociales" (Jenkins et al., 2015, p. 30).

La cultura participativa construye instancias críticas donde la información pasa a ser utilizada y reutilizada con motivo de generar un saber donde el conocimiento es compartido junto a una actividad crítica como proceso duradero" (Jenkins et al., 2010). Surge de este modo la inteligencia colectiva², gestada desde espacios de sentido donde la propia convergencia mediática es un fenómeno comunicacional que posibilita una participación del usuario activa y agenciadora, transformándose en mediador y creador de los propios medios que consume.

Por otra parte, es importante tener en cuenta que la narración transmedia tiene diversos fines. Si bien ha tenido mayor relevancia en el área económico-industrial, al ser considerada una estrategia eficaz de marketing principalmente en los universos de ficción hegemónicos, como el cine, la televisión y los videojuegos (Jenkins, 2008; Scolari, 2013), la realización transmedial también atiende causas sociales colectivas, visibilizando y denunciando desigualdades suscitadas en lógicas de poder económicas y culturales. Se debe remarcar que lo transmedial escapa a taxonomías que intentan reducirla a un producto de carácter subsidiario y comercial (Gifreu-Castells et al, 2019).

Es necesario atender el avance potenciado de las tecnologías digitales dentro de los medios de comunicación tradicionales sin perder de vista la importancia discursiva, a nivel de la forma y del contenido, que se fomenta desde las más variadas aristas de la representación de la realidad y contribuyen a su mejor entendimiento y comprensión en términos de la reflexividad. El empleo de producciones transmedia para evidenciar problemáticas colectivas permite que los movimientos sociales sean más efectivos cuando adoptan una movilización transmediática por medios de estrategias para desafiar el poder simbólico en entornos mediáticos complejos (Costanza-Chock, 2013).

Reconociendo la vitalidad del movimiento transmediático dentro de ámbitos comunicacionales hegemónicos, se permite llevar la información a los espacios públicos, los procesos políticos, el discurso mediático y la cultura popular, produciendo 
conocimiento sobre el mundo social (Cox y Flesher Fominaya, 2009). La transmedialidad opera sobre mecanismos de participación donde creadores y consumidores comparten un Llamado a la acción social por medio de la cultura participativa y la inteligencia colectiva. En este punto, el documental transmedia se diferencia de la realización documental tradicional:

Esa documentación/interpretación de la realidad va mediatizada por la elección de materiales, medios y plataformas y por las variables introducidas por lo transmediático en el espacio de la recepción, en el que se otorga a los prosumidores el estatus de co-creadores, lo que viene a trazar una brecha en la construcción y reconfiguración de la representación esa realidad con respecto a lo que sucede en el documental contemporáneo, independientemente de las retóricas y estéticas utilizadas. (Jiménez, 2016, p. 301)

Se comprende entonces al documental transmedia como un tipo de representación que mantiene las disposiciones concretas del discurso documental tradicional pero que propicia una dimensión dinámica de participación, creación y recepción: el usuario forma parte de la representación de la realidad que se establece desde el propio medio; lo digital pasa a ser un espacio contenedor de información, un ágora interactivo, participativo y contributivo (Gifreu-Castells, 2020).

Asimismo, la realización transmedia mantiene la función característica del cine documental tradicional: contribuir a la formación de la memoria colectiva sobre cuestiones, procesos y acontecimientos históricos con sus respectivas interpretaciones discursivas (Nichols, 1997). Este proceso de representación de la realidad explicita que "en el documental la narrativa transmedia encuentra un potente aliado, pues este permite una expansión del relato no tan compleja a la hora de jerarquizar el contenido y generar coherencia entre las diferentes plataformas" (Gifreu-Castells et al., 2019, 281).

Ferro (1991) manifiesta que el cine escribe la historia desde tres funciones distintas: como memoria e identidad, que sería el propio valor documental de la obra; como comunicación, que promueve una instancia de interacción entre realizador y espectador; y como análisis, que permite dar una inteligibilidad a los fenómenos históricos representados. En relación al documental transmedia, también se observa una necesidad de registro y preservación de la memoria, a la par de ser utilizado como vehículo comunicativo entre el contenido fílmico del realizador y la interpretación subjetiva del espectador, con motivo de generar reflexión en la cultura ciudadana.

La evolución tecnológica que ha tenido el cine documental, por lo tanto, no ha generado variación en sus postulados de representación originarios. Por el contrario, los documentales transmediáticos "encuentran condiciones ideales de proliferación en sociedades marcadas por la cultura de la convergencia" (Liuzzi, 2015, p. 107), donde a su vez los propios medios digitales facilitan la difusión de información, de conocimiento y contenidos educativos para el empoderamiento ciudadano (Zambrano y Gifreu-Castells, 2016).

\section{La presencia del discurso $\mathrm{LGBTQ}^{3}$ en la representación documental}

En esta idea de movimiento social y empoderamiento ciudadano, tomando como referencia las funciones de memoria/ identidad, comunicación y análisis del cine documental tradicional, resulta pertinente indagar de que forma los problemas culturales generados a causa de la desiguladad, la discriminación y la exclusión son representados en el contexto de convergencia mediática, cultura participativa e inteligencia colectiva de la era transmediática. En otras palabras, de qué manera las representaciones propias de la cultura visual han visibilizado asuntos complejos de la cultura para una mejor comprensión de los mismos desde los medios de comunicación.

En principio, el análisis de la cultura visual debe hacerse siempre dentro de la cultura más amplia a la que pertenece, poniendose en entredicho todo lo referido a lo visual, que se debate y se transforma como un lugar desafiante en términos de clase, género e identidad sexual y racial" (Mirzoeff, 2003). Desde la cultura visual, por medio del estudio de las imágenes y su agenciamiento con lo histórico, es posible interrogar si el documental transmediático es un tipo de discurso eficiente para arrojar luz sobre los procesos de marginación de determinados grupos sociales, asociados principalmente a cuestiones de género, y si puede proponer un margen de maniobra para incluir dichos problemas en el debate público.

Desde un punto de vista histórico, a partir de los años 70 el cine documental se centró en nuevos temas de carácter social, adoptando nuevos enfoques desde una mirada reflexiva alejada de estilos dominantes. Como expresa Nichols:

Nuevos temas y cuestiones como el movimiento de liberación de la mujer; los derechos de gays y lesbianas; el medio ambiente; etnicidad, raza, clase y nacionalidad; empresas multinacionales; SIDA; la falta de hogares; y los conflictos en América Central, Sudáfrica y el Oriente Medio son el tema de numerosos documentales e informes especiales de televisión. (1997, p. 14)

Con la representación del género y la sexualidad del discurso documental del último cuarto del siglo XX empiezan a surgir realizaciones que promueven la visibilización de grupos sociales minoritarios excluidos por la sociedad (homosexuales, transexuales, drag queens). Desde una perspectiva propia de la teoría queer, los estudios de género y, principalmente, del feminismo ${ }^{4}$ como movimiento cultural de resistencia y visibilización, se aportaron herramientas de las que carecía el discurso documental para una reconceptualización radical 
de la subjetividad y la política desde la concienciación de la reflexividad (Nichols, 1997)

En este contexto, es oportuno mencionar que la realización documental se entremezcla con la teoría cinematográfica, posibilitando un diálogo que entrecruza teoría y praxis, epistemología y acción, en el que el propio cine documental establece una reflexión crítica sobre el propio medio. Por este motivo, es importante tener en cuenta que las teorías cinematográficas sobre de la comunidad LGBTQI establecen un lugar de resistencia analítica sobre su representación en los medios audiovisuales:

A finales de los años setenta y principios de los ochenta, el terreno de los gender studies (estudios del género), surgidos simultáneamente a los women's studies, también abrió camino para los estudios gay y lésbicos (luego denominados queer studies). Numerosos teóricos vinculados a esos campos insistían en que las fronteras en la identidad genérica eran sumamente permeables y artificiales. (Stam, 2001, p. 302)

La visibilización de las problemáticas de las minorías sexuales en las últimas décadas abre un juego reflexivo en torno a los discursos que tomaban para sí su representación. Dentro de estos sectores marginados, se destaca la labor reflexiva suscitada desde la minoría transexual reescribiendo la narrativa heterosexual convencional, rompiendo con la dicotomía masculino-femenino, constiyuyendo una nueva posición de sujeto hablante y convirtiéndose en el significante mas transgresor de la sexualidad en juego, tanto en la cultura de la música popular como en el cine underground, el documental y el video experimental (Straayer, 1990). Desde esta perspectiva de visibilización, consideramos necesario explicitar que "los documentales sociales y culturales operan como un tipo de representación mediática para personas transgénero que sirve de vehículo para las auto-narrativas de los propios cuerpos marginados" (Johnson, 2016).

\section{La representación transmedial de la comunidad LGBTQI}

Si tenemos en cuenta los postulados mencionados en relación a la representación fílmica de la diversidad sexual, respaldando la idea que el cine documental fue partícipe de un contexto fundamental de visibilización sus problemáticas, surge una primera interrogante: ¿de qué forma las estrategias del documental transmedia continúan evidenciando dichos problemas culturales desde la convergencia mediática, la cultura de la participación y la inteligencia colectiva?

En el mismo orden de ideas, consideramos que el documental es un medio eficiente para reflexionar los problemas de las minorías sexuales. Por ejemplo, en el caso de la transexualidad se debe entender que la industria mediática influye tanto en como la sociedad ve la transexualidad como también en la forma en que los transexuales se autoperciben (Borba, 2020). Aquí nace un segundo cuestionamiento en torno a la visibilización de la comunidad LGBTQ̣I: ¿de qué forma dicho movimiento

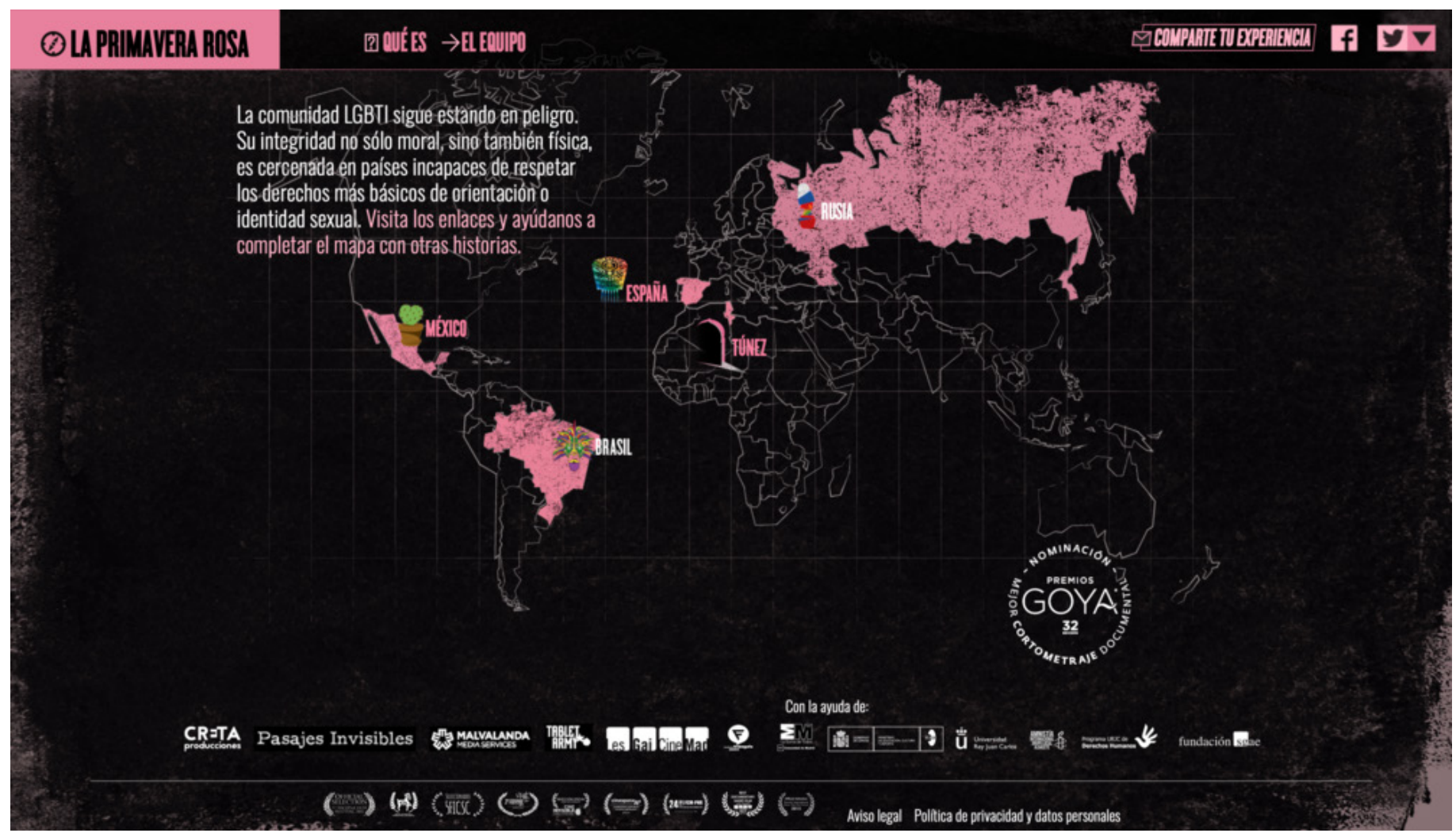

Figura 1. Inicio de la página web de la producción transmedia La primavera rosa. http://www.laprimaverarosa.com 
se autorepresenta en la era del documental transmediático en tanto se reconoce como voz enunciadora?

Para evidenciar las posibilidades del documental transmedia en explicitar las problemáticas de las minorías sexuales, se toman como objeto de estudio dos producciones transmediales realizadas en la última década (2010-2019) en Iberoamérica que se relacionan con la temática. Ambas obras promueven la movilización ciudadana y la participación activa de sus usuarios en un espacio horizontal de concientización sobre los problemas de la comunidad LGBTQI en el siglo XXI. Desde las interrogantes previamente sugeridas, se realizará un análisis de las prácticas sociales y colaborativas generadas en La primavera rosa, producción transmedia realizada en varios países a partir del año 2015, y La otra orilla, producción transmedia colombiana realizada entre 2016 y 2018.

\section{La primavera rosa y un enfoque transmedia multicultural}

La primavera rosa es un documental transmedia dirigido por Mario De la Torre Espinosa, con el apoyo de la Unión Europea, que se divulgó a través de diversas plataformas con la particularidad de que sus contenidos surgieron desde cinco países distintos: Brasil, México, España, Rusia y Túnez, versando sobre una temática en común: la ${ }^{5}$ problemática de la comunidad LGBTQI en diversos contextos geográficos. Lo transmedial, en este caso, recurre a lo que Gifreu-Castells (2015a) denomina posibilidades y combinaciones que son prácticamente infinitas, debido a que su producción recibe colaboraciones no limitadas geográficamente, alimentándose de una instancia colaborativa a nivel internacional.

Tomando como referencia las sociedades que bajo diversos marcos culturales tienen como objetivo la lucha por los Derechos Humanos en relación a la liberación sexual, La primavera rosa inició lo transmediático por medio de una serie en formato documental de cinco capítulos que pudieron verse por medio de su propia página de internet, y que luego tuvieron exhibición en servicios on demand, como la plataforma FILMIN, en salas cinematográficas y en festivales de diversos países, llegando incluso a tener amplia repercusión en el panorama de exhibición europeo ${ }^{6}$. Se evidencia, en esta multiplicidad de medios de difusión, la idea de convergencia mediática, que sin depender de un mecanismo de distribución específico anuncia un cambio de paradigma:

El paso de los contenidos específicos de un medio a los contenidos que fluyen por múltiples canales mediáticos a la creciente interdependencia de los sistemas de comunicación a los múltiples modos de acceder a los contenidos mediáticos y a relaciones cada vez más complejas entre los medios corporativos de arriba abajo y la cultura participativa de abajo arriba. (Jenkins, 2008, p. 241)

Como expresan Sánchez y López García (2021), el documental es el contenido más destacado en la mayoría de las producciones transmedia, puesto que hay una realidad que se entiende debe retratar, visibilizar y denunciar. La primavera rosa centra su contenido en dicho formato, en donde por cada capítulo se hace un seguimiento desde la toma de conciencia y la reflexión sobre las problemáticas de la comunidad LGBTQI acaecidas en el mundo histórico-material, por lo que "la web es la plataforma-madre que centraliza el proyecto, recoge lo desarrollado en la arena offline y remite a las distintas plataformas de la arena digital" (Sánchez y López García, 2021, p. 251).

La serie inició con el capítulo Hacia la primavera rosa, desarrollado íntegramente en Túnez, con una duración de 17 minutos. El producto muestra a diversos jóvenes árabes que forman parte de la comunidad LGBTQI tras el episodio de la Primavera Árabe con base a cuatro ejes temáticos: la transexualidad, la presencia de la diversidad sexual en zonas marginales del país, la imagen del homosexual en los medios y la sociedad tunecina, y el vinculo entre sofismo, religión y homosexualidad.

El segundo capítulo, de 19 minutos de duración, filmado en Rusia y titulado Primavera Rosa en el Kremlin, reflexiona sobre las nuevas medidas legales propuestas en 2013 por el presidente Vladimir Putin que discriminan y vejan a la población LGBTQI, en un régimen legal similar al practicado en el estalinismo, donde la homosexualidad era discriminalizada y considerada un delito. En el capítulo Primavera rosa en México, con un metraje de 23 minutos, se analiza la legalización del matrimonio homosexual tomando como referencia que el país ocupa el segundo lugar mundial en la tasa de asesinatos cometidos contra la comunidad LGBTQI. Además, se visibiliza el trabajo de activistas sexuales, como es el caso de la asociación Almas Cautivas A.C, dedicada a apoyar la población penitenciaria transexual en situaciones de vulnerabilidad.

El capítulo Primavera rosa en Brasil, de 26 minutos de duración, se ambienta en los Juegos Olímpicos de Río de Janeiro del año 2016, donde la comunidad LGBTQ̊ visibiliza las injusticias producidas hacia sus espacios, puesto que el país ocupa el primer lugar en crímenes ocurridos contra personas sexualmente diversas. Por último, el episodio Primavera rosa en España, con una duración aproximada de 20 minutos, se centra en la discriminación ocurrida en diversos centros educativos a jóvenes y adolescentes que, debido a su condición sexual, se adscriben a la colectividad sexual.

Más allá de su serialización, el total de duración de los cortometrajes (105 minutos) responde al metraje estándar de un largometraje tradicional, sin perder de vista su estrategia de visibilización de los problemas de la comunidad LGBTQ̣ en cuanto al contenido. Los cinco capítulos de la serie transme- 
dia mantienen la base epistemológica del cine documental, puesto que los espectadores se encuentran con experiencias que reexaminan y recontextualizan diversos hechos socioculturales (Nichols, 1997), manteniendo un discurso reflexivo sobre el rol de las minorías sexuales en la sociedad actual. A su vez, la producción responde al fin perseguido por la cultura visual, indagando en estrategias de representación que se centran en lo visual para crear y discutir significados (Mirzoeff, 2003, p. 24).

La expansión geográfica de contenidos a través de diversos países y continentes activan el ofrecimiento de una mirada plural y globalizada sobre una misma problemática, dentro de los marcos propios de la inteligencia colectiva, en donde uno de sus mecanismos de sentido consiste en crear o modificar representaciones y hacer evolucionar los signos en circulación (Lévy, 1999).

Por otra parte, además de la serie web, otros dos contenidos actúan a modo de complemento reforzando el mensaje de los cortometrajes documentales: un libro interactivo en formato digital titulado La primavera rosa: Identidad cultural y derechos humanos LGBTI en el mundo, producido y editado en cada país de realización; y una experiencia interactiva en formato VR 360. En el primer caso, se transita del lenguaje audiovisual (la webserie) hacia el lenguaje visual y escrito (el libro) recogiendo testimonios, crónicas de vida y experiencias de los diversos participantes de la serie desde una perspectiva cercana a la crónica periodística. El libro digital es un recurso aprovechado por las realizaciones transmedia ya que es una plataforma que se establece como documento colectivo con un destacado grado de profundidad y reflexión (Sánchez y López Gracia, 2021).

En otro orden, la experiencia en formato de realidad virtual permite que los espectadores, por medio de una visión en primera persona en $360^{\circ}$, participen de forma inmersiva dentro de la representación propuesta por la producción transmedia. El propio autor de la serie transmedia explica la experiencia:

La inmersión que ofrece las gafas de VR, la posibilidad de incorporarte a una conversación, ser el centro de atención de miradas o simplemente no poder escapar de imágenes que te desagradan, suponen un nuevo medio que nos permite empatizar con la realidad de los activistas. (De la Torre Espinosa, 2018, párr. 2).

La web también posee una sección denominada "Comparte tu experiencia", donde los usuarios envían relatos de sus vivencias enmarcadas en la diversidad sexual, lo que permite, por un lado, otorgarles un rol discursivo activo $y$, por otro lado, posibilita que la producción transmedia establezca una representación de las problemáticas de las minorías sexuales mediante la contribución de participantes que terminan inmersos en el proceso horizontal de la colaboración transmediática ciudadana.

La participación y compromiso de usuarios externos a la lógica de producción de La primavera rosa permite una reflexión comunitaria desde lo social por medio de la cultura participativa y la inteligencia colectiva, en donde la primera construye identidad cultural y social articulando imágenes de la cultura popular con preocupaciones no visibilizadas en los medios de comunicación hegemónicos (Jenkins y Tajter, 2010). La segunda, por su parte, pone en común ideas que promueven intereses comunes garantizando una amplia circulación de los mensajes (Jenkins, 2010).

Podemos afirmar que la realización de De la Torre Espinosa respeta la representación del documental tradicional sobre problemas sociales reales desde una forma de expresión interactiva con la suficiente fuerza emocional para provocar la acción (Gifreu-Castells, 2015b), por lo que puede ser entendido como un disparador del movimiento social en prácticas participativas de creación mediática a través de múltiples plataformas (Costanza-Chock, 2013).

Una característica fundamental de La primavera rosa es la capacidad de integrar historias de diversas partes del mundo por medio del lenguaje digital, traspasando fronteras de índole geográfica y posibilitando la pluralidad de relatos de minorias sexuales afincadas en multiples contextos culturales. Esto genera un acercamiento más complejo al reclamo y movilización de la comunidad LGBTQ̨ puesto que la multiculturalidad enriquece la observación de problemáticas compartidas en variados focos sociales.

El formato transmediático, en este caso, se presenta como una posibilidad que incitó también a la participación de los usuarios para completar las historias promovidas desde la producción del documental. Esto se puede ver reflejado tanto a la hora de agregar experiencias de vida como para también multiplicar los espacios donde la producción puede ser compartida mediante blogs, redes sociales o plataformas de consumo audiovisual, entre otros ámbitos de circulación de la interacción digital.

\section{La comunidad transexual y su representación transmediática en La otra orilla}

La otra orilla, producción realizada entre los años 2016 y 2018 por Margarita Herrera, es una realización transmedia cuyo objetivo es visibilizar los derechos de las personas y colectivos LGBTQI en Colombia, a través de diferentes formatos audiovisuales, interactivos y piezas de comunicación que buscan una concientización del tema. Arnau Gifreu-Castells, teórico e investigador del documental transmedia y su incidencia en los 


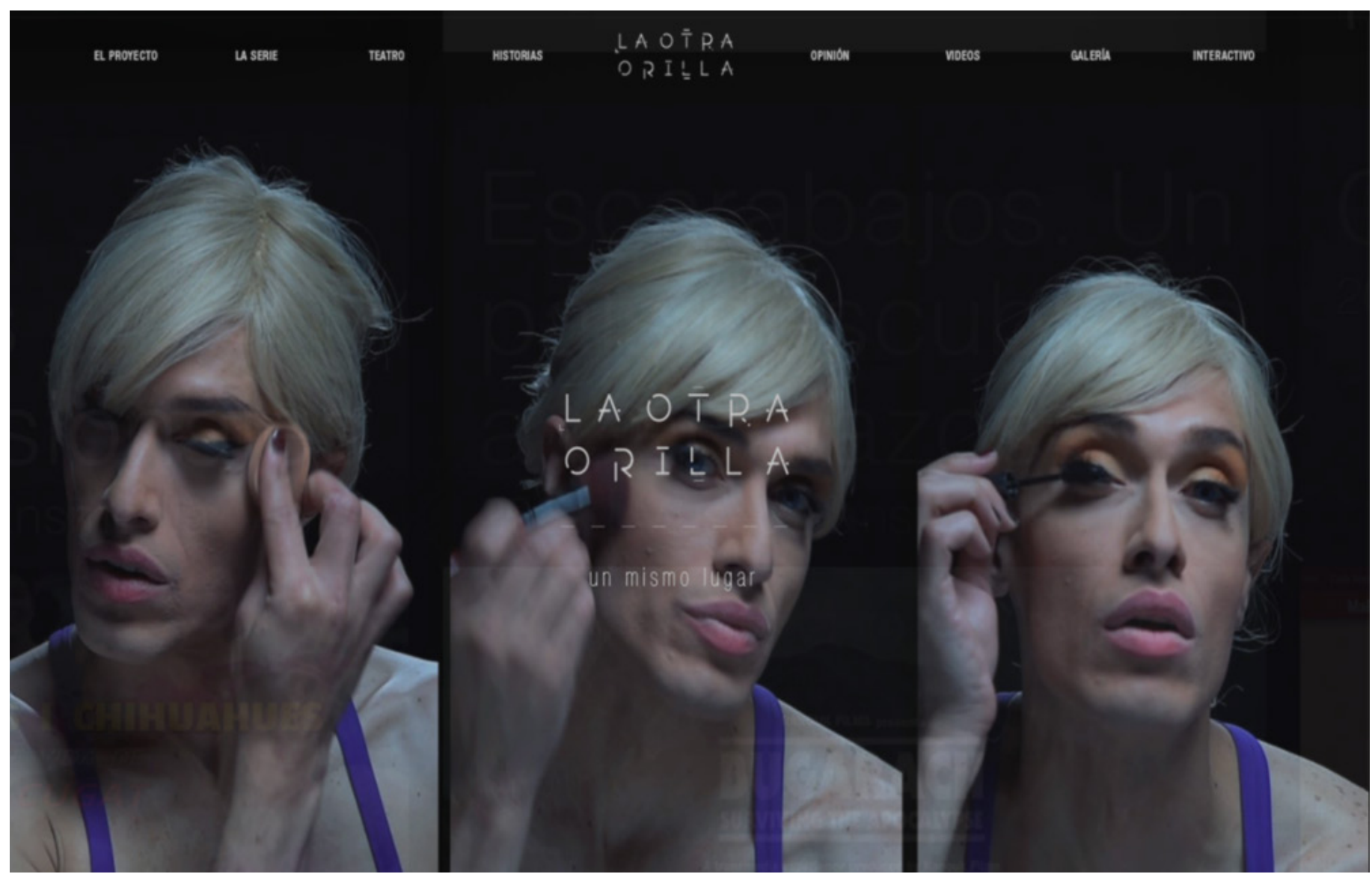

Figura 2. Inicio de la página web de la producción transmedia La otra orilla. http://www.laotraorilla.com.co

fenómenos de la comunicación, ofició de director de interactividad y transmedialidad del proyecto.

Esta producción audiovisual busca trasladar la experiencia de la comunidad LGBTQI a usuarios de diferentes géneros y edades con el objetivo de crear un espacio de interactividad desde el encuentro y el intercambio. La otra orilla se permite concebir como una obra que toma al movimiento social como eje de denuncia y evidenciación de los contratiempos culturales de la minoría sexual, dentro de un lugar de resistencia en el que la realización documental resulta un recurso eficiente:

Afecta y transforma la mirada sobre la importancia de una representación empoderadora y legitimada de la disidencia sexual en los medios de comunicación y la necesidad de la categoría en la ocupación de espacios sociales y políticos para que tengamos una sociedad y un mercado laboral justo e inclusivo. (Borba, 2020, p. 24)

La otra orilla se compone de diversos recursos que utilizan múltiples medios, soportes y lenguajes para generar su discurso. Por una parte, su núcleo temático central se explicita en una premiada ${ }^{7}$ serie de ficción de 12 capítulos de aproximadamente siete minutos de duración, que tienen como objetivo registrar testimonios de personas que fueron beneficiadas por la Corte Constitucional en el reconocimiento de sus derechos como personas LGBTQI. Además, la serie se transmitió desde el canal público Señal Colombia, que forma parte del sistema de medios públicos (RTVC).

Complementando a la serie, la producción se compone de una docena de relatos titulados Historias para ser, que exponen los avances sociales y culturales de la comunidad por medio de una serie fotográfica de carácter interactivo. Ligado a esto, también se realizó un videoblog de promoción de los derechos de las personas LGBTQI, una muestra fotográfica de 32 imágenes donde integrantes del colectivo hacen pública su identidad sexual e historias de vida y una segunda serie, titulada Teatro de mi propio ser, compuesta por 20 capítulos de 15 minutos de duración, en donde personas sexualmente diversas que habitan la región cafetera cuentan sus experiencias desde una representación cercana a lo teatral.

Dentro de los objetivos principales que se propone La otra orilla, se pueden evidenciar las prácticas colaborativas propias de la narrativa transmedia, el cine documental y los movimientos sociales debido a que, en primer lugar, trata de ofrecer información y exponer situaciones a las que se enfrentan diversas personas de la comunidad LGBTQ̊. Aquí, la convergencia mediática dice presente puesto que anima a un cambio cultural en donde la búsqueda de información se establece en conexiones suscitadas mediante contenidos mediáticos dispersos (Jenkins, 2008). Pero también hace aparición la inteligencia colectiva, puesto que uno de sus mecanismos consiste en 
modificar los afectos vinculados a diversas representaciones en circulación (Lévy, 1999). La producción transmedia evoca una instancia de información sobre la comunidad que se comparte horizontalmente en distintos medios, haciendo que se conozcan realidades marginales desde estrategias combinadas online-offline que amplían el universo generado desde lo digital (Sánchez y López García, 2021).

Es crucial comprender que La otra orilla permite dar voz a nuevas estructuras sociales dentro del panorama mediático digital. Esto también se evidencia en su segundo objetivo propuesto: trasladar la experiencia a los usuarios de la plataforma con el objetivo de que se pongan en la piel de los integrantes de la comunidad. La integración de la comunidad de usuarios al proyecto se afilia a una postura de participación y reflexión recíproca entre obra y receptor, desde un anclaje de interpretación activo.

La cultura participativa de La otra orilla concibe la idea de que "la cultura visual ahora se ha convertido en el emplazamiento de un cambio cultural e histórico" (Mirzoeff, 2003, p. 58), donde la actividad transmedia no sólo produce conocimiento sobre la sociedad, sino que también genera participación e información desde abajo (lo social) hacia arriba, donde se encuentran los medios, las disciplinas y los discursos hegemónicos (Cox y Fominaya, 2009). A su vez, la realización transmedia de Herrera se propone como objetivo aportar y dejar testimonios, más allá de cualquier identidad sexual, en un foro público de participación.

Particularmente, muchos de los contenidos generados en La otra orilla apuntan a una visibilización específicamente dedicada a la transexualidad, tomando en cuenta que las personas transexuales constituyen un discurso corporal desde una nueva posición de sujeto hablante y una estética alternativa de la presencia sexual de la mujer.

El deslindamiento de lo marginal de la transexualidad por parte de La otra orilla reafirma la cuestión que los documentales que cubren los fenómenos transgénero actúan como sustitutos de la experiencia de la vida real del ser transgénero (Johnson, 2016), posibilitando que el documental reflexione sobre la diversidad sexual reafirma condiciones de identidad dentro de la horizontalidad ciudadana, tanto en aspectos comunicacionales como en vertientes ideológicas.

La producción de Margarita Herrera indaga en específico sobre la discriminación existente hacia la comunidad transexual, en donde las protagonistas entrevistadas se reconocen víctimas de la marginación social. Es a partir de esta autoidentificación como sector social excluido desde donde las protagonistas deciden realizar un cambio sociocultural, abordando prejuicios, concientizando sobre los problemas cotidianos de la comunidad y promoviendo un llamado a la acción para la defensa de sus derechos.

Por estos motivos, la producción transmedia invita a la reflexión sobre la identidad de género y las disidencias sexuales apelando a múltiples formatos y lenguajes: notas periodísticas, blogs de opinión, relatos de vida, representaciones teatrales, miniproducciones audiovisuales, e incluso, la integración de otras disciplinas creativas como la danza o las artes plásticas. Se entiende, por lo tanto, al formato transmediático como una posibilidad interactiva y dinámica para la movilización social, apelando a un espacio discursivo multiforme incentivado por el lenguaje audiovisual que toma en cuenta a los usuarios.

La otra orilla genera una narrativa que toma formas de representación convencionales para integrarlas dentro de un nuevo espacio de sentido, que no olvida la condición ideológica de su mensaje y la comunidad LGBTQI que oficia de figura enunciadora. Se convierte en un ejemplo del despliegue técnico, narrativo y político que la realización transmediática puede tener desde el diálogo que generado por el propio lenguaje audiovisual digital.

\section{Conclusiones}

Tanto La primavera rosa como La otra orilla se erigen como ejemplos de documentales transmedia con fines sociales que se enmarcan dentro de prácticas y movimientos de colaboración ciudadana, generando un espacio de discusión sobre las minorías sexuales y su representación en los medios audiovisuales. El documental transmedia permite la construcción colectiva de representaciones no estigmatizantes a la par de visibilizar las problemáticas de la comunidad LGBTQI en su reclamo activo por defender y garantizar los Derechos Humanos desde la igualdad y la tolerancia.

Ambos documentales fomentan un proceso de autorrepresentación de las personas sexualmente diversas, que asumen un lugar de identidad y de identificación en relación a los usuarios que, desde la cultura participativa y la inteligencia colectiva, promueven la propia experiencia transmediática. El involucramiento de la sociedad en la propia estrategia de representación documental permite un vínculo más cercano entre comunicación, cultura y tecnologías digitales, evidenciando la importancia de estas últimas en el ámbito de la interacción de la vida cotidiana.

Por estos motivos, se intenta comprender que la producción transmediática con fines sociales puede ser el puntapié para generar cambios a nivel social y cultural, desde un uso integrado del lenguaje cinematográfico con otras formas de lenguaje audiovisual, con otros usos de soportes y nuevos espacios de interacción. De esta forma, se podrá evidenciar cual ha sido el impacto social de dichas producciones desde 
una mirada social que sea convergente con otras formas de conocimiento colectivo y participación a nivel mediática.

La convergencia mediática, dentro del panorama actual de la producción audiovisual digital, permite la proliferación de estrategias colaborativas en donde los movimientos sociales utilizan lo transmediático como herramienta colectiva, no solo en un sentido éticamente activista, sino con marcados fines ideológicos que inciden en los relatos que circulan en la sociedad de forma permanente.

Siguiendo este pensamiento, se debe comprender que La primavera rosa y La otra orilla realizan un ejercicio creativo desde la forma y el contenido, presentando un nuevo enfoque sobre las problemáticas de la comunidad LGBTIQ por medio de representaciones no estigmatizantes alejadas de estereotipos de género y/o sexuales. A través de una comunicación digital abierta a la comunidad, promueve la difusión y la reflexión desde el interés social, a través de un abordaje transversal a diversas disciplinas, medios de comunicación y formas de participación ciudadana.

Al tratarse de producciones audiovisuales que indagan problemáticas de índole social e ideológica, se promueve una interacción dialógica con la cultura acercando problemas de interés general a la comprensión pública. Potenciando también el vinculo entre diversos actores, ya sea sociales como también institucionales, con el objetivo de visibilizar la mirada que tiene el mundo histórico contemporáneo sobre la comunidad LGBTIQ.

\section{Notas al final}

1. El término transmedia fue asociado por primera vez a los medios de comunicación por Kinder (1991), al expresar que un texto individual forma parte de un discurso cultural más amplio, por lo que debe leerse en relación a otros textos y diversos múltiples supuestos ideológicos.

2. El concepto de inteligencia colectiva es propuesto por Lévy (1999) para referirse a la "capacidad de las comunidades virtuales para estimular el conocimiento y la pericia de sus miembros mediante la colaboración y deliberación a gran escala" (Jenkins, 2010, p. 245).

3. Se entiende por este acrónimo al colectivo de minoría sexuales integrado por movimientos lésbicos, gays, bisexuales, transexuales, queer e intersexuales. En los últimos años, se han sumado al acrónimo la presencia de otros integrantes del colectivo como los asexuales, demisexuales y pansexuales, identificados en muchos casos con el símbolo "+" al final del término.

4. Straayer (1990) entiende que el feminismo, en lugar de la cultura popular y los artistas transexuales, debe ser reconocido por este empoderamiento de lo femenino, del cual la misma comunidad transexual ha realizado una apropiación ideológica y simbólica a lo largo de la historia.

5. Tanto La otra orilla como La primavera rosa han tenido actividad en redes sociales y plataformas digitales masivas. En el caso de la primera, utilizó Facebook, Instagram y Twitter como medios de comunicación activos, al igual que YouTube, en donde posee más de 60 videos publicados con un aproximado de 20000 visualizaciones. En el caso de la segunda, ha tenido participación activa en las redes sociales Facebook, Instagram y Twitter.

6. El capítulo surgido en México obtuvo una nominación al Premio
Goya del cine español como Mejor cortometraje documental, mientras que el capítulo de España fue nominado al Premio ASECAN del cine andaluz. El capítulo de Brasil fue galardonado con el Premio Madrid en Corto por el Madrid Short Film Week, mientras que el capítulo de Rusia también fue nominado al Premio ASECAN y compitió en el Festival Internacional de Cine de Miskolc (Jameson CineFest) en la categoría Cortometraje y cine experimental.

7. La serie recibió el Premio de la ANTV (Autoridad Nacional de Televisión) en la categoría de ficción en el año 2016 y fue nominada a los $34^{\circ}$ Premios India Catalina de la Industria Audiovisual Colombiana en la categoría Mejor producción online en el año 2018. Como proyecto, también resultó ganador en el año 2016 del Estímulo a la producción de una Serie de Televisión que aborda temas de la cultura regional colombiana. Por último, La otra orilla integró la Selección Oficial del 20 Festival Internacional de Nuevas Narrativas de No Ficción, en la categoría transmedia.

\section{Bibliografía}

Borba, N. (2020). Disclosure-Ser trans más allá de la pantalla: cuando la vida imita el arte, aunque el arte no imite la vida. Entramados: educación y sociedad, 7(8), 19-25. https://dialnet.unirioja.es/ servlet/articulo?codigo $=7771471$

Conde, M. S. (2019). Microrrelato y virtualidad: empleo de los mecanismos de la minificción en la Realidad Virtual. Microtextualidades. Revista Internacional de microrrelato y minificción, 6(1), 95-102. https://revistas.uspceu.com/index.php/microtextualidades/article/ view/155/148

Costanza-Chock, S. (2013). Transmedia Mobilization in the Popular Association of the Oaxacan Peoples, Los Angeles. En: B. Cammaerts, A. Mattoni y P. McCurdy, (Eds.), Mediation and Protest Movements (pp. 97-114). Intellect.

Cox, L., y Flesher Fominaya, C. (2009). Movement knowledge: what do we know, how do we create knowledge and what do we do with it? Interface: a journal for and about social movements, 1(1), 1-20. http:// www.interfacejournal.net/wordpress/wp-content/uploads/2010/11/ interface-issue-1-1-pp1-20-Editorial.pdf

De La Torre Espinosa, M. (2018). La primavera rosa: Identidad cultural y derechos humanos LGBTI en el mundo. Editorial UOC.

Ferro, M. (1991). Perspectivas en torno a las relaciones Historia-Cine. Filmhistoria online. (1), 3-12. https://revistes.ub.edu/index.php/ filmhistoria/article/view/12148/14901

Gifreu-Castells, A. (2015a). Evolución del concepto de no ficción. Aproximación a tres modelos narrativos. Obra digital: revista de comunicación, (8), 14-39. https://www.raco.cat/index.php/ObraDigital/article/view/301174/390728

Gifreu-Castells, A. (2015b). El uso del documental transmedia como herramienta para el cambio social. Análisis de casos focalizados en las desigualdades de género en el siglo XXI. Congreso Internacional Comunicación, Sociedad Civil y Cambio Social. Universitat Jaume I, 1154-1177. Fragua.

Gifreu-Castells, A., Sánchez Castillo, S. y Galán Cubillo, E. (2019). Aproximación al documental interactivo como formato nativo transmedia. Pasavento, (275), 275-302. http://repositori.uji.es/xmlui/ handle/10234/187090?locale-attribute=en

Gifreu-Castells, A. (2020). Documental Interactivo como Narrativa Compleja: Autor, Receptor, Modelo de Negocio y Preservación. En R. Longhi, A. Lovato y A. Gifreu-Castells (Eds.), Narrativas Complexas (pp. 75-95). Ria Editorial.

Jenkins, H. (2008). Convergence Culture. La cultura de la convergencia 
de los medios de comunicación. Paidós.

Jenkins, H., y Tatjer, A. C. (2010). Piratas de textos: fans, cultura participativa y televisión. Paidós.

Jenkins, H., Ford, S. y Green, J. (2015). Cultura transmedia. La creación de contenido y valor en una cultura en red. Gedisa.

Jiménez, A. G. (2016). Documental y narrativa transmedia: Estrategias creativas y modelos de producción [Tesis de Doctorado, Universidad de Sevilla]. https://idus.us.es/handle/11441/47911

Johnson, A. H. (2016). Transnormativity: A new concept and its validation through documentary film about transgender men. Sociological Inquiry, 86(4), 465-491. https://doi.org/10.1111/soin.12127

Kinder, M. (1991). Playing with Power in Movies, Television, and Video Games: From Muppet Babies to Teenage Mutant Ninja Turtles. University of California Press.

Lévy, P. (1999). ¿Qué es lo virtual?. Paidós.

Liuzzi, A. (2015). El documental interactivo en la era transmedia: de géneros híbridos y nuevos códigos narrativos. Obra digital: revista de comunicación, (8), 105-135. https://doi.org/10.25029/od.2015.52.8

Mirzoeff, N. (2003). Una introducción a la cultura visual. Paidós.

Nichols, B. (1997). La representación de la realidad. Paidós.

Sánchez, C. C., y López-García, X. (2021). Narrativas transmedia sociales en el ámbito hispanoamericano (2014-2018). Arte, Individuo y Sociedad, 33(1), 237-257. https://doi.org/10.5209/aris.67561
Scolari, C. (2013). Narrativas transmedia. Cuando todos los medios cuentan. Deusto.

Stam, R (2001). Teorías del cine. Una introducción. Paidós.

Straayer, C. (1990). The She-man: Postmodern bi-sexed performance in film and video. Screen, 37(3), 262-280. https://doi.org/10.1093/ screen/31.3.262

Zambrano, V. M., y Gifreu-Castells, A. (2016). Aproximación al potencial colaborativo de la narrativa documental interactiva en los procesos de cambio social. Cultura, lenguaje y representación: revista de estudios culturales de la Universitat Jaume I, (15), 153-169. https:// doi.org/10.6035/clr.2016.15.10

\section{CV}

Santiago López Delacruz. Licenciado en Comunicación por la Universidad de la República de Uruguay. Maestrando en Información y Comunicación. Docente del Departamento de Medios y Lenguajes de la Facultad de Información y Comunicación.

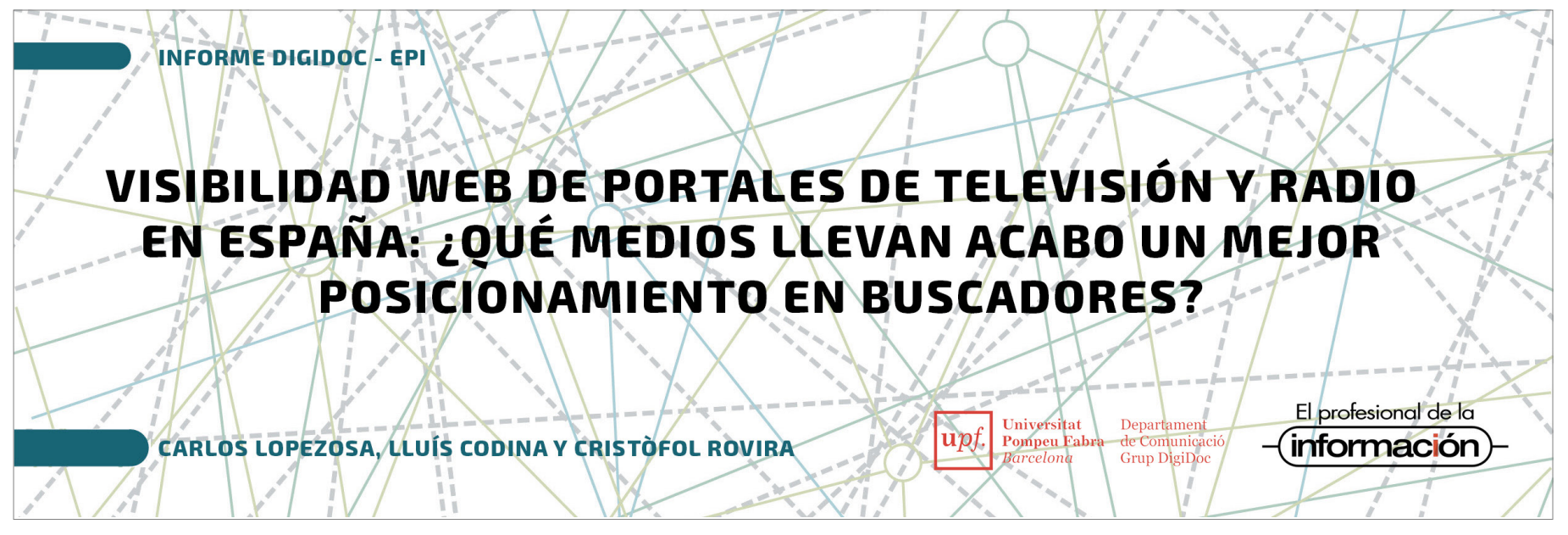

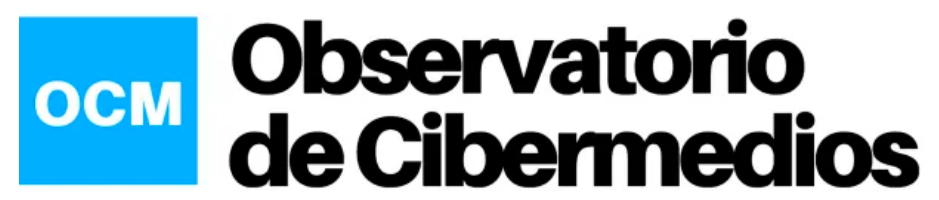

https://observatoriocibermedios.upf.edu/

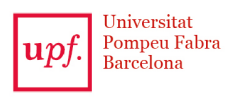

Departamento
de Comunicació Grupo DigiDoc

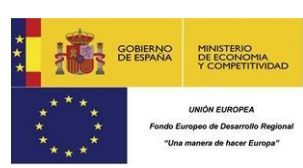

El Observatorio de Cibermedios es una producción del Grupo de Investigación en Documentación Digital y Comunicación Interactiva (DigiDoc) del Departamento de Comunicación de la Universitat Pompeu Fabra.

El Observatorio de Cibermedios (OCM) forma parte del proyecto del Plan Nacional "Narración interactiva y visibilidad digital en el documental interactivo y el periodismo estructurado". RTI2018-095714-B-C21 (MINECO/FEDER), Ministerio de Ciencia, Innovación y Universidades (España). 